\title{
HOMENAGEM DA SOCIEDADE BRASILEIRA DE QUÍMICA AO PROFESSOR HANS VIERTLER
}

Este número de Química Nova faz parte das homenagens que a Diretoria e o Conselho Consultivo da Sociedade Brasileira de Química, SBQ, em conjunto com os Editores de Química Nova, está fazendo ao nosso colega e amigo Professor Hans Viertler na passagem do seu $70^{\circ}$ aniversário.

Este número é composto por 28 artigos (3 na área de Educação), 12 revisões e 3 notas técnicas, apresentados por cerca de 190 autores e abrangendo uma grande variedade de sub-áreas da química. O primeiro artigo destaca a carreira do professor Hans e o material suplementar associado registra a fusão das apresentações feitas por cada um dos autores: na homenagem conjunta SBQ-CRQ IV, na sessão que correu em 04 de fevereiro de 2010 na sede do CRQ IV, em São Paulo e na homenagem feita pelo Instituto de Química da USP em 12/3/2010.

O Professor Hans tem uma contribuição expressiva à Ciência e à Química, a sua atuação como professor do Instituto de Química da USP revela um profissional dedicado à formação de recursos humanos qualificados, através da geração do conhecimento científico e tecnológico. Demonstra, ainda, uma atuação marcante em favor da profissão de químico no âmbito do Conselho Regional de Química da $4^{\mathrm{a}}$ Região e uma atuação dedicada na SBQ.

A contribuição de Hans à SBQ foi (e é) inestimável! Ocupou várias posições formais na gestão da SBQ: Tesoureiro (2 mandatos), Secretário Geral (2 mandatos), Vice-Presidente, Presidente e Conselheiro (5 mandatos). Nestas posições sempre atuou na direção de que a SBQ deveria desenvolver a capacidade de influir: na elaboração de políticas de C\&T; na construção dos currículos de graduação e pós-graduação; no desenvolvimento do setor industrial e no cenário internacional.

Durante a sua gestão como Presidente, iniciou os contatos com a Federação Latinoamericana de Química (FLAQ), em Concepción, Chile, 1996, e com os Presidentes das Sociedades de Química da América Latina e Caribe, que resultaram na assinatura do acordo de cooperação (1996) que selou a participação da SBQ na FLAQ.

Foi durante a Presidência de Hans que a SBQ iniciou o hábito de preparar documentos norteadores da Ciência e Tecnologia no Brasil. O marco foi "A contribuição da Química ao Desenvolvimento Científico e Tecnológico do País", que propôs investimentos para a aquisição de equipamentos e apoio à graduação, pós-graduação e aos jovens doutores, abrindo o caminho para a elaboração dos "Eixos Mobilizadores de Química", um marco para a SBQ e para os documentos que se seguiram.

Os leitores deste número especial que não são sócios da $\mathrm{SBQ}$, bem como alguns "jovens sócios" podem perguntar, por que a SBQ decidiu homenagear Hans? A melhor resposta está dada por um amplo conjunto de profissionais e sócios destacados da SBQ, que constam do Material Suplementar do artigo "Hans Viertler: Professor, Cientista, Gestor e AMIGO", listados a seguir:
Prof. Claudio Luis Donnici, DQ-UFMG; Prof. Glaucius Oliva, IF-USP São Carlos; Dr. Simon Campbell, ex-Presidente da Royal Society of Chemistry; Prof. Etelvino Bechara, IQ-USP, ExPresidente da SBQ; Prof. Peter Bakuzis, IQ-UnB; Prof. Roberto Rittner, IQ-UNICAMP; Prof. Aécio P. Chagas, IQ-UNICAMP; Prof. Paulo R. Olivato, IQ-USP; Prof. Raimundo Braz Filho, Ex-Reitor da UENF, Ex-Presidente da SBQ; Prof. Marco Aurelio De Paoli, IQ-UNICAMP, Ex-Presidente da SBQ; Prof. Romeu C. Rocha Filho, DQ-UFSCar; Prof. Carlos Alberto Filgueiras, IQ-UFRJ, Ex-Presidente da SBQ; Profa. Fernanda Ferraz Camilo, UNIFESP - Diadema; Prof. Jonas Gruber, IQ-USP; Prof. Paulo Cezar Vieira, DQ-UFSCar, Ex-Presidente da SBQ; Prof. Vitor Francisco Ferreira, DQ-UFF; Prof. Oswaldo Luiz Alves, IQ-UNICAMP, Ex-Presidente da SBQ; Dra. Denise Curi, Colégio Bandeirantes, ex-aluna de Doutorado; Prof. Francisco Comninos, Universidade de Guarulhos, ex-aluno de Doutorado; Dra. Camila S. Gonçalves, Insulation Technology, ex-aluna de Mestrado; Prof. Antônio S. Mangrich, DQ-UFPR, Ex-Presidente da SBQ; Profa. Vanderlan da Silva Bolzani, UNESP - Araraquara, Ex-Presidente da SBQ; Prof. Hernan Chaimovich, IQ-USP, Vice-Presidente da ABC; Prof. Paschoal Senise, IQ-USP; Profa. Ursula Brocksom, DQ-UFSCar; Profa. Ana Maria Ferreira, IQ-USP; Prof. Henrique Toma, IQ-USP; Prof. Ivano Gutz, IQ-USP, Coord. da OQSP; Prof. Timothy J. Brocksom, DQ-UFSCar; Airton Ferreira Gonçalves, Assistente Técnico de Direção IV-Acadêmico, IQ-USP.

A leitura dos depoimentos dos colegas revela o tamanho da contribuição do Professor Hans à Química e, em especial, à SBQ. Dois depoimentos, que não constam do Material Suplementar, resumem o sentimento de todos os que conviveram e convivem com Hans:

"Uma das características do Prof. Hans Viertler é a sua capacidade de ouvir e a maneira atenciosa e educada com que trata situações difíceis. Só achamos que não há mais jeito, que o conflito está instalado, quando o Hans não está por perto". Professor Angelo Pinto, IQ-UFRJ, Ex-Presidente da SBQ.

"Hans é um amigo porreta!" Professor Antonio Celso Spinola Costa, Professor Emérito, UFBA.

Em resumo, o Professor Hans Viertler é um exemplo para a sua geração e as futuras de Professor, Cientista, Gestor e AMIGO, cujo coração é maior que ele próprio.

Jailson B. de Andrade (IQ-UFBA) Editor Convidado Susana I. Córdoba de Torresi (IQ-USP) Editora de QN Vitor F. Ferreira (IQ-UFF) Editor de QN 